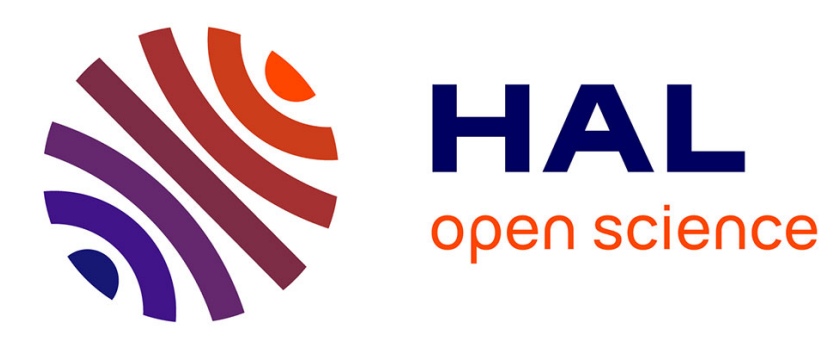

\title{
Validation of an ion-pair liquid chromatography-electrospray-tandem mass spectrometry method for the determination of heterocyclic aromatic amines in meat-based infant foods \\ Lisa Elviri
}

\section{To cite this version:}

Lisa Elviri. Validation of an ion-pair liquid chromatography-electrospray-tandem mass spectrometry method for the determination of heterocyclic aromatic amines in meat-based infant foods. Food Additives and Contaminants, 2007, 24 (08), pp.833-841. 10.1080/02652030701278339 . hal-00577287

\section{HAL Id: hal-00577287 \\ https://hal.science/hal-00577287}

Submitted on 17 Mar 2011

HAL is a multi-disciplinary open access archive for the deposit and dissemination of scientific research documents, whether they are published or not. The documents may come from teaching and research institutions in France or abroad, or from public or private research centers.
L'archive ouverte pluridisciplinaire HAL, est destinée au dépôt et à la diffusion de documents scientifiques de niveau recherche, publiés ou non, émanant des établissements d'enseignement et de recherche français ou étrangers, des laboratoires publics ou privés. 


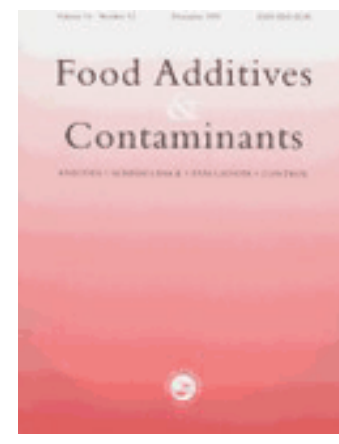

\section{Validation of an ion-pair liquid chromatography- electrospray-tandem mass spectrometry method for the determination of heterocyclic aromatic amines in meat- based infant foods}

\begin{tabular}{|r|l|}
\hline Journal: & Food Additives and Contaminants \\
\hline Manuscript ID: & TFAC-2006-337.R1 \\
\hline Manuscript Type: & Original Research Paper \\
\hline Date Submitted by the \\
Author: & 06-Feb-2007 \\
\hline Complete List of Authors: & $\begin{array}{l}\text { Elviri, lisa; Università di Parma, Dipartimento di Chimica Generale } \\
\text { ed Inorganica, Chimica Analitica, Chimica Fisica }\end{array}$ \\
\hline Methods/Techniques: & Chromatography - LC/MS, In-house validation, Method validation \\
\hline Additives/Contaminants: & Hetrocyclic amines \\
\hline Food Types: & Baby food \\
\hline & \\
\hline
\end{tabular}

\section{SCHOLARONE ${ }^{\text {M }}$ Manuscripts}




\begin{abstract}
A method based on ion-pair liquid chromatography electrospray tandem mass spectrometry (LCMS/MS) is reported for determining heterocyclic aromatic amines (HAAs) in meat-based infant foods. The HAAs encompassed quinoline (IQ, MeIQ), quinoxaline (MeIQx), pyridine (PhIP) and carboline derivatives (A $\alpha \mathrm{C}$, Harman, Norharman) with $\mathrm{d}_{3}-\mathrm{IQ},{ }^{13} \mathrm{C}_{2}-\mathrm{MeIQx}$ and $\mathrm{d}_{3}-\mathrm{PhIP}$ used as labeled internal standards. The method used extraction into acetone followed by a clean-up on an SCX solid-phase extraction column. LC separation was performed on a TSKgel ODS-80TS column $(250 \times 2.0 \mathrm{~mm}, 5 \mu \mathrm{m})$, the mobile phase being an ammonium formate-formic acid buffer $(3.03 \mathrm{mM}$ ammonium formate, $\mathrm{pH}=2.8$ ) aqueous solution-acetonitrile gradient at a flow rate of $0.2 \mathrm{ml} \mathrm{min}^{-1}$. For unequivocal identification of each analyte, three ions were detected and chosen for selected reaction monitoring (SRM). Validation was carried out on lyophilized meat samples. Mean recoveries ranged between $78 \pm 4 \%$ and $98 \pm 2 \%$ for different analytes. Limits of quantification generally lower than $8 \mathrm{ng} / \mathrm{g}$ were demonstrated in meat samples for the analytes investigated. The method exhibited good linearity and repeatability. Robustness testing identified those factors which were statistically significant in influencing chromatographic separation and response, and indicated which parameters have to be strictly controlled for a reliable analysis of HAAs. In particular, mobile phase flow-rate was found to be statistically significant $(\alpha=0.05)$ for the capacity factor $\left(\mathrm{k}^{\prime}\right)$ of all analytes except for $\mathrm{A} \alpha \mathrm{C}$ peak, whereas mobile phase $\mathrm{pH}$ resulted to be a critical parameter for the k' values of IQ, MeIQ and Norharman. The method proved to be robust versus resolution between IQ and MeIQ peaks. Among mass spectrometric parameters, collision energy was found to significantly affect quantitative response of all analytes except that of IQ. The applicability of the method to the analysis of meat-based infant food samples was demonstrated.
\end{abstract}


Keywords: Heterocyclic aromatic amines; Ion-pair liquid chromatography-mass spectrometry; Validation; Robustness

\section{Introduction}

Heterocyclic aromatic amines (HAAs) are substances of great concern for food safety being recognized as potent mutagenic compounds to which humans are regularly exposed through diet and ambient environments [Skog et al. 1998]. These compounds are formed in thermally treated protein-rich foods at the $\mathrm{ng} / \mathrm{g}$ level, but they are also detected in several other environments, including cooking fumes, cigarette smoke, air, rain, and river water [Kataoka, 1997].

For the unambiguous identification and determination of these mutagenic and carcinogenic substances in different kinds of food commodities it is therefore necessary to develop and validate fast and reliable analytical methods. Due to the great complexity of food matrices and the low concentration levels of HAAs, their identification and determination require a comprehensive analytical approach involving the use of efficient sample preparation techniques and the employment of hyphenated analytical techniques. Solid-phase extraction (SPE) under cationic exchange and reversed-phase mechanisms have been described as the most widely used methods for their isolation and clean-up [Gross and Grüter, 1992; Toribio et al., 1999]. High-performance liquid chromatography (HPLC), gas chromatography (GC), and capillary electrophoresis have been used for separation purposes [Knize et al., 1992; Pais, and Knize, 2000]. At the present the most widely applied technique for HAA analysis is liquid chromatography coupled with mass spectrometry (LCMS), since LC-MS-based techniques allow to avoid time-consuming derivatization procedures needed prior to GC-MS determination. In particular, LC coupled with tandem mass spectrometry (MS-MS) using both triple quadrupole and ion trap mass 
spectrometers have proved highly successful in the determination of HAAs [Klassen et al 2002; Toribio, et al 2002; Barceló-Barrachina et al., 2004a; 2004b]. The applicability of a LCelectrospray-quadrupole time of flight (ESI-QTOF)-MS and LC-ESI-QTOF-MS/MS techniques for the identification and determination of HAAs in foods has been also investigated using high mass accuracy measurements [Barceló-Barrachina et al., 2004b]. Very recently a low-time consuming solid-phase extraction procedure was developed together with a liquid chromatography-ion trap mass spectrometry method for their determination in griddled beef steak [Toribio, et al., 2006].

In our research work dealing with the investigation of the separation of HAAs (figure 1) by reversed-phase ion-pair LC-MS/MS [Bianchi, et al., 2005], we demonstrated that under gradient conditions the use of an eluent containing formate buffer at $\mathrm{pH} 2.8$ proved more effective in terms of chromatographic behaviour and detectability of these analytes than the use of a mobile phase containing the acetate buffer, which is commonly used for the analysis of HAAs.

The need of a standard methodology and validated analytical methods for HAAs analysis is actually of great interest. In particular, interlaboratory exercises of the determination of HAAs in meat extract laboratory reference materials have been recently presented highlighting the importance to improve the quality of the analytical measurements [Santos et al., 2004.].

In this context the aim of the present work was the single-laboratory validation of the previously developed chromatographic method to be applied to meat-based infant foods to measure their HAA content. A procedure entailing solvent extraction and clean-up by SPE was used. Besides to linearity, limit of detection (LOD), limit of quantificattion (LOQ), accuracy and recovery, attention was focused to the evaluation of method robustness towards both chromatographic and mass spectrometric parameters.

\section{Experimental}

\section{Chemicals}


Harman (1-methyl- $\beta$-carboline) and norharman (9H-pyrido[3,4- $b$ ] indole) were from Sigma-Aldrich (Germany). IQ (2-amino-3-methyl-3H-imidazo[4,5-f]quinoline), MeIQ (2-amino-3,4-dimethyl-3Himidazo[4,5-f]quinoline), MeIQx (2-amino-3,8-dimethylimidazo[4,5-f]quinoxaline), PhIP (2-amino1-methyl-6-phenylimidazo[4,5-b]pyridine), $\mathrm{A} \alpha \mathrm{C}$ (2-amino-9H-pyrido[2,3-b]indole), Isotopically labelled IQ-D $3,{ }^{13} \mathrm{C}_{2}$-MeIQx e $\mathrm{D}_{3}$-PhIP were from Toronto research Chemicals Inc. (Canada).

Stock standard solutions of HAAs and internal standards at concentrations of $0.5 \mathrm{mg} / \mathrm{mL}$ were prepared in methanol and stored in the dark at $4^{\circ} \mathrm{C}$. Working standard solutions were prepared daily for a better stability by diluting stock solutions with HPLC-grade water. Ammonium formate, formic acid, HPLC-grade acetonitrile and HPLC-grade water were from Carlo Erba (Milan, Italy).

\section{Liquid chromatography-mass spectrometry}

An Alliance 2690 liquid chromatograph (Waters, Milford, MA, USA) equipped with a 120-vial capacity sample management system was used. Chromatographic separation was obtained using a TSKgel ODS-80TS (250 x $2.0 \mathrm{~mm}, 5 \mu \mathrm{m})$ (TOSOH BIOSEP, Germany) column under gradient conditions. The mobile phase consisted of a mixture of ammonium formate-formic acid buffer $(\mathrm{pH}=2.8)(\mathrm{v} / \mathrm{v})$ aqueous solution (eluent $\mathrm{A})$ and acetonitrile (eluent B) delivered at a flow-rate of 0.2 $\mathrm{mL} \mathrm{min}^{-1}$. The gradient was as follows: at $0 \mathrm{~min} 5 \% \mathrm{~B}$, in $20 \mathrm{~min} 54.5 \% \mathrm{~B}$ hold for 3 min, back to $5 \% \mathrm{~B}$ in $3 \mathrm{~min}$ and $10 \mathrm{~min}$ to re-equilibrate the column.

A Quattro LC triple quadrupole-mass spectrometer (Micromass, Manchester, UK) with a pneumatically-assisted electrospray interface was used. Data acquisition was performed in positive ion mode $(\mathrm{ESI}(+))$. Interface parameters were set as follows: capillary voltage $2.8 \mathrm{kV}$, cone voltage $50 \mathrm{~V}$ (IQ, MeIQ, MeIQx, Norharman, Harman, PhIP) and $40 \mathrm{~V}(\mathrm{~A} \alpha \mathrm{C})$, extractor lens voltage $2 \mathrm{~V}$, source temperature $110^{\circ} \mathrm{C}$, desolvation temperature $240^{\circ} \mathrm{C}$, rf lens $0.1 \mathrm{~V}$. The nebulizer and desolvation gases (nitrogen, $99.999 \%$ high-purity) were delivered at $60 \mathrm{~L} \mathrm{hr}^{-1}$ and $550 \mathrm{~L} \mathrm{hr}^{-1}$ respectively.

Experiments for optimization of ESI interface parameters were performed by directly infusing solutions into the ESI-MS system at a flow-rate of $6 \mu \mathrm{L} \mathrm{min}{ }^{-1}$. Full-scan analyses were performed over the scan range $\mathrm{m} / \mathrm{z}$ 150-300 using a step size of $0.1 \mathrm{Da}$ and a rate of 0.4 scans/s. Operating in MS/MS mode, product-ion scan mass spectra of protonated molecules were acquired in the $\mathrm{m} / \mathrm{z} 30$ 300 range. Selected reaction monitoring $(\mathrm{SRM})$ analyses were performed as follows: $\mathrm{m} / \mathrm{z} 199 \rightarrow 184$ (collision energy, CE $26 \mathrm{eV}$ ), m/z 199 $\rightarrow 157$ and m/z $199 \rightarrow 130(\mathrm{CE} 40 \mathrm{eV}$ ) for IQ, m/z 202 $\rightarrow 184$ 


\section{Samples.}

\section{Solvent extraction and SPE procedure}

Beef-based infant foods were purchased in big trades. Three homogenized and one lyophilized beefbased infant foods coming from different manufacturers were analyzed. Horse-, lamb-, rabbit- and chicken-based infant foods from three different manufactures were also analyzed.

To $1.0 \mathrm{~g}$ of homogenized sample weighed into a polypropylene graduated conical tube with cap 12 $\mathrm{mL}$ of acetone. After mixing for $5 \mathrm{~min}$ on a vortex, the extract was centrifuged at $4800 \mathrm{rpm}$ (1350 g) for $5 \mathrm{~min}$. Extraction was performed twice. The clarified solution was removed and stored in the freeze $\left(-18^{\circ} \mathrm{C}\right)$ for one hour to allow protein to precipitate. The mixture was centrifuged at $4800 \mathrm{rpm}$ $(1350 \mathrm{~g})$ for $5 \mathrm{~min}$ and $24 \mathrm{~mL}$ of the final extract were loaded on the SPE cartridges. Strong cation exchange (benzenesulfonic-SCX bonded silica) cartridges (300 mg, $6 \mathrm{~mL}$ ) (Supelco) were used for concentration and clean-up purposes. Cartridges were first conditioned with $4 \mathrm{~mL}$ of methanol and $4 \mathrm{ml}$ acetone, 24-mL sample were then loaded and eluted with 4- $\mathrm{ml} 2 \mathrm{M}$ ammonium acetate aqueous solution/acetone $(50 / 50, \mathrm{v} / \mathrm{v})$. The volume of the final extract was then reduced to $2 \mathrm{~mL}$ in a graduate vial by evaporating acetone under a nitrogen stream. The sample was filtered and directly injected (injection volume $30 \mu \mathrm{l}$ ) onto the LC system.

Sample treatment based on solvent extraction followed by SPE was carried out three times for each sample and three LC replicate analyses were run for each extract.

Recovery studies were carried out by spiking samples of lyophilized meat at two different concentration levels (10 and $50 \mathrm{ng} / \mathrm{g}$ ) with appropriate volumes of the working mixtures of HAAs. 
The mixture was left to stand overnight at $4^{\circ} \mathrm{C}$. The sample was equilibrated to room temperature before following the extraction procedures above described.

\section{Validation of the LC-ESI-MS/MS method}

Validation of the developed method was carried out following EURACHEM guidelines [Anon, 1998] on a lyophilized meat matrix extracted and purified using the procedure described.

Detection limit $\left(\mathrm{y}_{\mathrm{D}}\right)$ and quantitation limit $\left(\mathrm{y}_{\mathrm{Q}}\right)$ were preliminarly calculated as signals based on the mean blank $\left(\overline{x_{b}}\right)$ and the standard deviation $\left(s_{\mathrm{b}}\right)$ of the blank signals as follows:

$$
\mathrm{y}_{\mathrm{D}}=\overline{\boldsymbol{x}_{\boldsymbol{b}}}+2 t \mathrm{~s}_{\mathrm{b}} \quad \mathrm{y}_{\mathrm{Q}}=\overline{\boldsymbol{x}_{\boldsymbol{b}}}+10 \mathrm{~s}_{\mathrm{b}}
$$

where $t$ is a constant of the $t$-Student distribution (one-sided) depending on the confidence level and the degrees of freedom ( $v=n-1, n=$ number of measurements). Ten blank measurements were performed to calculate $\overline{x_{b}}$ and $\mathrm{s}_{\mathrm{b}}$. A lyophilized beef based sample extract in which the analytes were verified to be absent was used as the blank matrix. $\mathrm{y}_{D}$ and $\mathrm{y}_{\mathrm{Q}}$ were converted from the signal domain to the concentration domain to estimate limit of detection (LOD) and limit of quantitation (LOQ) respectively, using an appropriate calibration function. In order to satisfy basic requirements such as homoscedasticity and linearity, the Bartlett test and the Mandel's fitting test were performed at the $95 \%$ confidence level.

Linearity was established over two orders of magnitude of concentration calculating matrixmatched calibration curves. $\mathrm{d}_{3}-\mathrm{IQ},{ }^{13} \mathrm{C}_{2}$-MeIQx and $\mathrm{d}_{3}$-PhIP labelled internal standard was used. Six equi-spaced concentration levels were chosen and three replicated injections were performed at each level. Homoscedasticity test was run and the goodness of fit of the calibration curve was assessed by applying the lack-of-fit and Mandel's fitting tests [Funk et al., 1995]. A $t$-test was carried out to verify the significance of the intercept (confidence level 95\%).

Accuracy was tested in terms of precision and trueness. Precision was calculated in terms of intraday and between-day repeatability as R.S.D.\% at two concentration levels (10 and $50 \mathrm{ng} / \mathrm{g}$ ).

Trueness was evaluated by calculating the recovery function [Funk et al., 1995], which allows to assess both constant and proportional systematic errors.

Robustness of the analytical method was tested using a two-level Plackett-Burman (PB) design. Eleven factors (eight real factors and three dummy variables) were considered and 12 experiments were carried out. The PB design was applied in order to identify the critical factors influencing the following responses: relative peak area (analyte area/IS area) (IQ, MeIQ, MeIQx, Norharman, 
Harman, PhIP, AaC); resolution (Rs) (IQ, MeIQ); capacity factor (k') (IQ, MeIQ, MeIQx, Norharman, Harman, PhIP, A $\alpha$ C); asymmetry factor (T) (IQ, MeIQ, MeIQx, Norharman, Harman, $\mathrm{PhIP}, \mathrm{A} \alpha \mathrm{C})$. Eight critical factors which were believed to affect the chromatographic results were chosen, three of which referred to the mass spectrometer: the mobile phase flow-rate $(\mathrm{ml} / \mathrm{min})$, the percentage of organic modifier (acetonitrile) at the beginning and at the end of the gradient (\%), the $\mathrm{pH}$ and the concentration of ammonium formate in the mobile phase, the column temperature $\left({ }^{\circ} \mathrm{C}\right)$, the cone voltage $(\mathrm{V})$, the capillary voltage $(\mathrm{kV})$ and the collision energy applied in the collision cell of the mass spectrometer $(\mathrm{eV})$. Experimental conditions were set selecting symmetrical values around the nominal level which reflected the variations that could be encountered in laboratory during the mobile phase preparation or due to instrumental fluctuations (9-20\% of the nominal value) (Tables 1 and 2). The three dummy variables included in the design were used to evaluate the variability of the procedure. The effects were calculated as follows:

$$
E_{X}=\frac{\sum Y(+)}{N / 2}-\frac{\sum Y(-)}{N / 2}
$$

where $E_{X}$ is the effect of factor $\mathrm{X}$ on response $\mathrm{Y} ; \mathrm{Y}(+)$ and $\mathrm{Y}(-)$ are the responses where $\mathrm{X}$ is at the level (+) and (-) respectively, $\mathrm{N}=12$ is the total number of experiments.

The standard error (SE) was evaluated using the dummy variables as follows:

$$
(S E) e=\sqrt{\frac{\sum E_{\text {dummy }}^{2}}{n_{\text {dummy }}}}
$$

Significance of an effect was evaluated at both $\alpha=0.05$ and $\alpha=0.01$ significance levels. An effect was considered significant at a given $\alpha$ level if $\left|\mathrm{E}_{\mathrm{X}}\right|>\mathrm{E}_{\text {critical }}=t_{\text {critical }}(\mathrm{SE})_{\mathrm{e}}$, where $t$ is a constant of the $t$-Student distribution (one-sided) depending on the confidence level and the degrees of freedom ( $v=n-1, n=$ number of measurements). The matrix of experiments is illustrated in Table 3 . The experiments were carried out in random order and for each experiment a single injection was performed. Two experiments at the nominal level (one before and one after the experimental design execution) were run in order to assess the absence of instrumental drift. Method robustness was evaluated at $100 \mu \mathrm{g} / \mathrm{L}$ level on standard solutions. A blank injection was performed prior to each analysis.

All statistical analyses and tests were performed by using the statistical package SPSS v. 9.0 for Windows (SPSS, Bologna, Italy). 


\section{Results and Discussion}

\section{$L C$-ESI(+)-MS and-MS/MS performances}

The separation of the investigated analytes was performed in less than 20 min with good resolution [Toribio, et al., 2006] (figure 2).

Under $\mathrm{ESI}(+)-\mathrm{MS}$ conditions, mass spectra of all compounds showed predominant $[\mathrm{M}+\mathrm{H}]^{+}$ ions without fragmentation. The description of the product ion MS/MS spectra as obtained by low-energy collision-induced dissociation of protonated HAA molecules were previously depicted [Toribio, et al., 2006]. HAA extraction was performed from meat samples by using acetone as already proposed by Felton et al. [1981; 1984] who successfully applied this solvent for HAA separation from food by liquid-liquid extraction.

In the development of the SPE procedure for purification and concentration of HAAs in meat products, mixtures of acetone/aqueous solution of ammonium acetate at different concentrations (0.5, 2 and $3 \mathrm{M})(50 / 50)$ were evaluated as eluting solvents. The method was assessed on the basis of the qualitative and quantitative results obtained on the meat-based food used in this work. The best results were obtained by using $2 \mathrm{M}$ ammonium acetate aqueous solution/acetone (50/50, v/v). Under these conditions, recovery values ranging from $78 \pm 4 \%$ to $98 \pm 2 \%$ (RSD<12\%, $\mathrm{n}=12$ ) were obtained for the analytes.

SPE extracts did not show the presence of any interference in correspondence to the transitions monitored for the amines. However, suppression effects were observed in correspondence to the peaks of all the analytes, suggesting the presence of not detected co-eluting matrix compounds in the extracts. On the basis of these findings, further investigation on matrix suppression effect was performed during method validation.

\section{Calibration and method performances}

To check method performance, quality parameters such as robustness, detection limit, quantification limit, linearity range, precision and trueness were studied in matrix. 
Since the LC-MS/MS method developed is intended for routine use, its robustness, i.e. the capacity to remain unaffected by small variations in nominal experimental conditions, was tested at the beginning of the validation procedure. For this purpose, a screening design such as the PlackettBurman was used. Factors were selected among those that are most likely to be controlled when a method is transferred between laboratories and that could influence the responses of the method. The results of the robustness test in terms of the effects of the different factors on the considered responses are shown in Table 4. The factors having a statistically significant effect on a response at significance level of 1 and $5 \%$ were indicated. Relative peak area resulted to be significantly affected both by chromatographic and MS/MS parameters. In particular, under the conditions used in this work, the analyte-internal standard area ratio resulted to be affected by mobile phase flowrate, ion pair reagent concentration, column temperature (only for MeIQx), cone voltage (only for $\mathrm{A} \alpha \mathrm{C}$ ), collision energy (for all analytes except for MeIQx and IQ). These findings suggest that these parameters should be strictly controlled for a reliable quantification of HAAs. None of the factors resulted to have significant effect on resolution between IQ and MeIQ peaks. The results obtained for the other factors evidenced that mobile phase flow-rate was found to be statistically significant $(\alpha=0.05)$ for the capacity factor of all analytes except for A $\alpha \mathrm{C}$ peak. In addition, mobile phase $\mathrm{pH}$ resulted to be a critical parameter for the k' values of IQ, MeIQ and norharman.

Under the optimized chromatographic and MS/MS conditions, operating in SRM mode, LOD and LOQ of HAAs in lyophilized meat samples were at levels lower than 5 and $8 \mathrm{ng} / \mathrm{g}$ respectively, except for PhIP (Table 5).

Using external calibration, good linearity of the method was established over two orders of magnitude $\left(\mathrm{r}^{2}=0.998-0.999, \mathrm{n}=18\right)$ on both solvent and matrix. Linearity was demonstrated by verifying homoscedasticity over the range tested (Bartlett test) and by applying the Mandel fitting test (Table 5. The latter showed that a quadratic regression did not provide a better fitting than the linear one.

Excellent precision in terms of intra-day repeatability was calculated, RSD\% values ranging from 1 to $4 \%(n=5)$ for all the analytes. Between-day precision calculated over three days provided RSD values lower than $10 \%$ for IQ, MeIQx and PhIP, whereas greater variability was observed for the analysis of MeIQ and A $\alpha \mathrm{C}$, being calculated RSD of ca. $25 \%$ for these compounds. 
Finally, the calculation of the recovery functions to test trueness of the developed method was performed by spiking and analyzing lyophilized meat samples. The intercepts of the recovery functions calculated from these data were compared with 0 by means of a $t$-test. For all analytes the $t$ values calculated for the intercepts were lower than the tabulated value at $95 \%$ confidence level, thus demonstrating that constant systematic errors are not present. Instead, the presence of proportional systematic errors was evidenced, since slope values of the recovery functions were demonstrated to be significantly different from $1(\mathrm{p}<0.05)$. These findings suggest that to attain accuracy in the quantitative analysis of HAAs in lyophilized meat samples the use of the internal labelled standard method is recommended.

\section{Determination of HAAs in meat based infant foods using the LC-ESI-MS/MS method}

The applicability of the LC-ESI-MS/MS method was then evaluated for the identification and determination of heterocyclic aromatic amines in meat-based infant foods.

With the aim to adding confidence to the identity of the analyte, three fragmentation transitions per compound present in the samples were monitored, thus complying with MS confirmation criteria as established by 1999/333/EG [20]. After confirmation, the quantitative assay of HAAs identified in the samples was performed using suitable calibration curves (Table 6). Among the samples investigated, norharman and harman were detected in all samples considered at concentrations up to $8.9 \pm 0.3$ and $19 \pm 3 \mathrm{ng} / \mathrm{g}$ respectively, whereas MeIQx was detected only in one beef-based infant sample at a concentration value under the quantification limit. Figure 3 illustrates the LC-ESI(+)MS/MS extract transition chromatograms of the HAAs investigated in one infant food sample.

\section{Conclusions}

This study validated the ion pair HPLC under gradient conditions and ESI(+)-MS/MS detection method for the simultaneous determination of a number of heterocyclic aromatic amines in beefbased infant foods. Even if lower detection limits are demanded in this kind of application, valuable information was achieved from the robustness study, which indicated those factors with statistical significance which influence chromatographic separation and response.

The evaluation of matrix effects by means of the recovery function allowed us to exclude the presence of constant systematic errors, not otherwise detectable by using a labelled internal standard. The validation data demonstrate that this method is convenient for routine analysis of 
heterocyclic aromatic amines in meat products, since a good repeatability was shown and detection limits and quantification limits were in the low ng/g level.

\section{Acknowledgements}

This work was financially supported by MIUR (Ministero dell'Istruzione, dell'Università e della Ricerca, Italy), COFIN 2002 Project "Food safety. New analytical methods for the control of natural trace contaminants".

\section{References}

Anon (1998) The Fitness for Purpose of Analytical Methods 1998: A Laboratory Guide to Method Validation and Related Topics, Eurachem Guide, $1^{\text {st }}$ English Edition 1.0, LGC (Teddington) Ltd; http://www.eurachem.ul.pt

Barceló-Barrachina, E.; Moyano, E.; Puignou, L.; Galceran, M.T.; 2004a. Evaluation of different liquid chromatography-electrospray mass spectrometry systems for the analysis of heterocyclic amines J. Chromatogr. A 1023: 67-78

Barceló-Barrachina, E.; Moyano, E.; Galceran, M.T.; 2004b. Determination of heterocyclic amines by liquid chromatography-quadrupole time-of-flight mass spectrometry J. Chromatogr. A 1054: 409-418.

Bianchi, F.; Careri, M.; Corradini, C.; Elviri, L.; Mangia, A.; Zagnoni, I.; 2005. Investigation of the separation of heterocyclic aromatic amines by reversed phase ion-pair liquid chromatography coupled with tandem mass spectrometry: the role of ion pair reagents on LC-MS/MS sensitivity J. Chromatogr. B 825: 193-200.

Felton, J. S., S. Healy, D. Stuermer, C. Berry, H. Timourian, F.T. Hatch, (1981) Mut. Res. 88, 33.

Felton, J.S., M.G. Knize, C. Wood, B.J. Wuebbles, S.K. Healey, D.H. Stuermer, L.F. Bjeldanes, B.J. Kimbles, F.T. Hatch, (1984) Carcinogenesis 5, 95. 
Funk, W.; Dammann, V.; Donnevert, G. 1995 Quality Assurance in Analytical Chemistry, VCH, Weinheim.

Gross, G.A.; Grüter. A.; 1992. Quantitation of mutagenic/carcinogenic heterocyclic aromatic amines in food products. J. Chromatogr. 592: 271-278

Kataoka.H.; 1997. Methods for the determination of mutagenic heterocyclic amines and their applications in environmental analysis J. Chromatogr. A 774: 121-142.

Klassen, R.D.; Lewis, D.; Lau, B.-P.Y.; Sen, N.P.; 2002. Heterocyclic aromatic amines in cooked hamburgers and chicken obtained from local fast food outlets in the Ottawa region. Food Res. Int. 35: 837-847.

Knize, M.G.; Felton, J.S.; Gross, G.A.; 1992. Chromatographic methods for the analysis of heterocyclic amine food mutagens/carcinogens. J. Chromatogr. 624: 253-265.

Pais, P.; Knize, M.G.; 2000. Chromatographic and related techniques for the determination of aromatic heterocyclic amines in foods. J. Chromatogr. B 747: 139-169.

Santos, F. J.; Barceló-Barrachina, E.; Toribio, F.; Puignou, L.; Galceran, M. T.; Persson, E.; Skog, K.; Messner, C.; Murkovic, M.; Nabinger, U.; Ristic, A.; 2004. Analysis of heterocyclic amines in food products: interlaboratory studies. J. Chromatogr. B 802: 69-78

Skog, K.; Johansson, M. A.; E., Jägerstad M.; 1998. Carcinogenic heterocyclic amines in model systems and cooked foods: a review on formation, occurrence and intake. Food and Chemical Toxicology 36: 879-896.

Toribio, F.; Puignou, L.; Galceran. M.T.; 1999. Evaluation of different clean-up procedures for the analysis of heterocyclic aromatic amines in a lyophilized meat extract.J. Chromatogr. A 836: 223233. 
Toribio, F.; Moyano, E.; Puignou, L.; Galceran, M.T.; 2002. Ion-trap tandem mass spectrometry for the determination of heterocyclic amines in food J. Chromatogr. A 948: 267-281.

Toribio, B.F.; Busquets, R.; Puignou, L.; Galceran, M.T.; 2006. Heterocyclic Amines In Griddled Beef Steak Analysed Using A Single Extract Clean-Up Procedure. Food Chem. Toxycol. available on-line. 
Table 1

Factors investigated in the Plackett-Burman design of robustness test

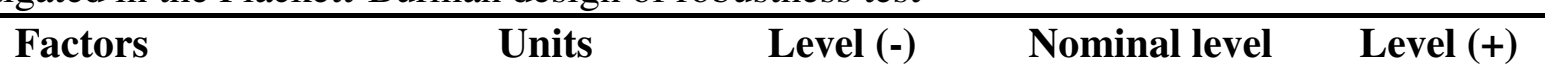

(0)

\begin{tabular}{|c|c|c|c|c|}
\hline Mobile phase flow-rate & $\mathrm{ml} / \mathrm{min}$ & 0.18 & 0.2 & 0.22 \\
\hline Ion pair reagent concentration & $\mathrm{mM}$ & 2.73 & 3.03 & 3.33 \\
\hline $\mathrm{pH}$ of the buffer & - & 2.52 & 2.8 & 3.08 \\
\hline Column temperature & ${ }^{\circ} \mathrm{C}$ & 30 & 35 & 40 \\
\hline $\begin{array}{l}\text { Percentage organic modifier }(\% \mathrm{~B}) \text { in } \\
\text { the mobile phase at the start of the } \\
\text { gradient }\end{array}$ & $\%$ & 4.5 & 5 & 5.5 \\
\hline $\begin{array}{l}\text { Percentage organic modifier }(\% \mathrm{~B}) \text { in } \\
\text { the mobile phase at the end of the } \\
\text { gradient }\end{array}$ & $\%$ & 52 & 54.5 & 57 \\
\hline Collision energy & $\mathrm{eV}$ & $-{ }^{*}$ & $0 *$ & $+*$ \\
\hline Cone voltage & V & $-*$ & $0^{*}$ & $+*$ \\
\hline
\end{tabular}


Table 2. Cone voltage and collision energy values used for each analyte in the PB design.

\begin{tabular}{|c|c|c|c|c|c|c|}
\hline \multirow[t]{2}{*}{ Analyte } & \multicolumn{2}{|c|}{ Level (-) } & \multicolumn{2}{|c|}{$\begin{array}{c}\text { Nominal level } \\
(0)\end{array}$} & \multicolumn{2}{|c|}{ Level (+) } \\
\hline & $\begin{array}{c}\mathrm{CE} \\
(\mathrm{eV})\end{array}$ & $\begin{array}{c}\text { cone } \\
\text { voltage } \\
(\mathrm{V})\end{array}$ & $\begin{array}{c}\mathrm{CE} \\
(\mathrm{eV})\end{array}$ & $\begin{array}{c}\text { cone } \\
\text { voltage } \\
\text { (V) }\end{array}$ & $\begin{array}{c}\mathrm{CE} \\
(\mathrm{eV})\end{array}$ & $\begin{array}{c}\text { cone } \\
\text { voltage } \\
(\mathrm{V})\end{array}$ \\
\hline IQ & 24 & 27 & 26 & 50 & 29 & 55 \\
\hline MeIQ & 45 & 45 & 27 & 50 & 30 & 55 \\
\hline MeIQx & 24 & 27 & 40 & 50 & 44 & 55 \\
\hline Norharman & 45 & 36 & 32 & 50 & 35 & 55 \\
\hline Harman & 36 & 24 & 50 & 50 & 55 & 55 \\
\hline $\mathrm{PhIP}$ & 45 & 45 & 30 & 50 & 33 & 55 \\
\hline $\mathrm{A} \alpha \mathrm{C}$ & 29 & 27 & 30 & 45 & 33 & 44 \\
\hline $\mathrm{D}_{3-} \mathrm{IQ}$ & 45 & 45 & 27 & 50 & 30 & 55 \\
\hline${ }^{13} \mathrm{C}_{2}-\mathrm{MeIQx}$ & 45 & 29 & 30 & 50 & 33 & 55 \\
\hline $\mathrm{D}_{3}$-PhIP & 45 & 50 & 32 & 55 & 35 & 61 \\
\hline
\end{tabular}


Table 3

Matrix of the Plackett- Burman design (- = low factor level, + = high factor level)

\begin{tabular}{ccccccccccccc}
\hline Experiment No. Factors $^{\mathrm{a}}$ & & & & & & & & \\
\cline { 2 - 9 } & $\mathrm{A}$ & $\mathrm{B}$ & $\mathrm{C}$ & $\mathrm{D}^{\mathrm{b}}$ & $\mathrm{E}$ & $\mathrm{F}$ & $\mathrm{G}$ & $\mathrm{H}$ & $\mathrm{I}^{\mathrm{c}}$ & $\mathrm{J}$ & $\mathrm{K}$ \\
\hline 1 & + & + & - & + & + & + & - & - & - & + & - \\
2 & + & + & - & - & - & + & - & + & + & - & + \\
3 & - & + & + & - & + & + & + & - & - & - & + \\
4 & - & + & + & + & - & - & - & + & - & + & + \\
5 & - & + & - & + & + & - & + & + & + & - & - \\
6 & + & + & + & - & - & - & + & - & + & + & - \\
7 & + & - & + & + & + & - & - & - & + & - & + \\
8 & + & - & + & + & - & + & + & + & - & - & - \\
9 & - & - & + & - & + & + & - & + & + & + & - \\
10 & + & - & - & - & + & - & + & + & - & + & + \\
11 & - & - & - & - & - & - & - & - & - & - & - \\
12 & - & - & - & + & - & + & + & - & + & + & +
\end{tabular}

${ }^{\mathrm{a}}$ (A) mobile phase flow rate (mL/min); (B) salt concentration (mM); (C) dummy 1; (D) collision energy $(\mathrm{eV})$; (E) dummy 2; (F) acetonitrile at the start of the gradient $(\%)$; $(\mathrm{G})$ dummy 3; (H) acetonitrile at the end of the gradient $(\%)$; (I) cone voltage $(\mathrm{V}) ;(\mathrm{J})$ column temperature $\left({ }^{\circ} \mathrm{C}\right) ;(\mathrm{K}) \mathrm{pH}$ of the buffer.

b,c The values used for each analyte are reported in Table 2 
Table 4

Results of the robustness test in terms of the effects of the different factors on the considered responses

\begin{tabular}{|c|c|c|c|c|c|c|c|c|}
\hline \multirow[t]{2}{*}{ Analyte } & \multicolumn{8}{|c|}{ Factors } \\
\hline & $\mathbf{A}^{1}$ & $\mathbf{B}^{1}$ & $\mathbf{C}^{1}$ & $\mathbf{D}^{1}$ & $\mathbf{E}^{1}$ & $\mathbf{F}^{1}$ & $\mathbf{G}^{1}$ & $\mathbf{H}^{1}$ \\
\hline IQ & $\mathbf{k}^{\prime * *}$ & & & & & & & $\mathbf{k}^{\prime * *}$ \\
\hline MeIQ & $\mathbf{k} * *$ & As $* *$ & $\mathbf{A} / \mathbf{A}_{\mathbf{I S}} * *$ & $\mathbf{k}^{\prime} * *$ & & & $\begin{array}{c}\mathbf{k}^{* *} \\
\mathbf{A} \mathbf{s}^{* *}\end{array}$ & $\mathbf{k}^{\prime * *}$ \\
\hline MeIQx & $\begin{array}{c}\mathbf{k}^{\prime * *} \\
\mathbf{A} / \mathbf{A}_{\mathbf{I S}} * *\end{array}$ & $\mathbf{A} / \mathbf{A}_{\mathbf{I S}} * *$ & & & & & $\mathbf{A} / \mathbf{A}_{I S} * *$ & \\
\hline Norharman & $\begin{array}{l}\mathbf{k} * * * \\
\mathbf{A s}^{* * *}\end{array}$ & & $\mathbf{A} / \mathbf{A}_{\text {IS }} * *$ & & & & & $\begin{array}{l}\mathbf{k}^{\prime * * *} \\
\mathbf{A s}^{* * *}\end{array}$ \\
\hline Harman & $\mathbf{k} * *$ & & $\mathbf{A} / \mathbf{A}_{\mathbf{I S}} * *$ & & & & & \\
\hline PhIP & $\begin{array}{l}\mathbf{k} * * \\
\mathbf{A s} \mathbf{s}^{* *}\end{array}$ & & $\mathbf{A} / \mathbf{A}_{I S} * *$ & & & & & \\
\hline $\mathrm{A} \alpha \mathrm{C}$ & & & $\mathbf{A} / \mathbf{A}_{\mathbf{I S}} * *$ & & & $\mathbf{A} / \mathbf{A}_{\mathbf{I S}} *$ & & \\
\hline
\end{tabular}

(A) mobile phase flow-rate; (B) ion-pair reagent concentration; (C) collision energy; (D) organic modifier percentage at the start of the gradient; (E) organic modifier percentage at the end of the gradient; (F) cone voltage; (G) column temperature; $(\mathrm{H}) \mathrm{pH}$ of the buffer

* Significance level 5\%.

** Significance level $1 \%$. 


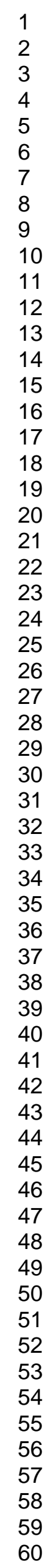


Table 5

LOD and LOQ values and matrix-matched calibration curves established in lyophilized meat extracts using LC-ESI-MS/MS method.

Calibration function: $\mathrm{y}=\mathrm{b}_{1} \mathrm{x}$.

\begin{tabular}{|l|c|l|c|c|c|c|}
\hline Analyte & LOD & LOQ & $\begin{array}{c}\text { Concentration range } \\
(\mathrm{ng} / \mathrm{g})\end{array}$ & $\begin{array}{c}\text { Homoscedasticity } \\
\text { test }^{\mathrm{b}}\end{array}$ & $\begin{array}{c}\text { Mandel's } \\
\text { test }^{\mathrm{b}}\end{array}$ & $\mathrm{b}_{1}\left( \pm \mathrm{s}_{\mathrm{b} 1}\right)^{\mathrm{b}}$ \\
\hline $\begin{array}{c}\text { Matrix: } \\
\text { lyophilized } \\
\text { meat } \\
(\mathrm{ng} / \mathrm{g})^{\mathrm{a}}\end{array}$ & 5.4 & 7.8 & $10-1000$ & 0.11 & 0.23 & $0.93( \pm 0.03)$ \\
\hline IQ & 1.8 & 3.8 & $10-1000$ & 0.06 & 0.51 & $1.98( \pm 0.08)$ \\
\hline MeIQ & 4.1 & 8.1 & $10-1000$ & 0.08 & 0.06 & $0.367( \pm 0.013)$ \\
\hline MeIQx & 0.5 & 1.0 & $1-500$ & 0.12 & 0.05 & $2.37( \pm 0.12)$ \\
\hline Norharman & 0.5 & 1.0 & $1-500$ & 0.34 & 0.21 & $4.3( \pm 0.2)$ \\
\hline Harman & 12 & 26 & $40-2200$ & 0.25 & 0.47 & $0.073( \pm 0.002)$ \\
\hline PhIP & 3.7 & 7.4 & $40-1350$ & 0.45 & 0.19 & $0.63( \pm 0.02)$ \\
\hline A $\alpha C$ & & & & & \\
\hline
\end{tabular}

${ }^{\text {a }}$ Referred to $1 \mathrm{~g}$ sample extracted with $2 \mathrm{~mL}$ solvent. See Experimental.

${ }^{\mathrm{b}}$ Confidence level $95 \%$. 
Table 6

Determination of HAAs in infant meat based samples ${ }^{\text {a }}$

\begin{tabular}{|l|c|c|c|c|c|}
\hline Analyte & Beef $^{\text {a }}$ & Chicken $^{\mathbf{a}}$ & Horse $^{\mathbf{a}}$ & Lamb $^{\mathbf{a}}$ & Rabbit $^{\mathbf{a}}$ \\
\hline IQ & \multicolumn{5}{|c|}{$(\mathrm{ng} / \mathrm{g})$} \\
\hline MeIQ & $-{ }^{\mathrm{b}}$ & - & - & - & - \\
\hline MeIQx & - & - & - & - & - \\
\hline Norharman & $8.9 \pm 0.3$ & $6.3 \pm 0.5$ & $7.4 \pm 0.3$ & $8.7 \pm 0.3$ & $5.4 \pm 0.2$ \\
\hline Harman & $19 \pm 3$ & $6.4 \pm 0.8$ & $11.1 \pm 0.7$ & $10.7 \pm 0.8$ & $9.2 \pm 0.6$ \\
\hline PhIP & - & - & - & - & - \\
\hline A $\alpha \mathrm{C}$ & - & - & - & - & - \\
\hline
\end{tabular}

${ }^{\mathrm{a}}$ Three different brands. Number of samples for each brand: 3 . Results not corrected by the recovery.

b $-=$ not detected. 
Figure 1. Chemical structures of heterocyclic aromatic amines investigated.

Figure 2. LC-ESI(+)-MS/MS extracted ion chromatograms of a standard solution of HAAs (100 $\mu \mathrm{g} / 1)$. For chromatographic and MS7MS conditions see Experimental.

Figure 3. LC-ESI(+)-MS/MS product ion mass spectra of a standard solution of HAAs (100 $\mu \mathrm{g} / \mathrm{l})$. For chromatographic and MS7MS conditions see Experimental.

Figure 4. LC-ESI(+)-MS/MS extracted ion chromatograms of HAAs identified in an homogenized beef-based infant food sample extract. 


\section{Figure 1}

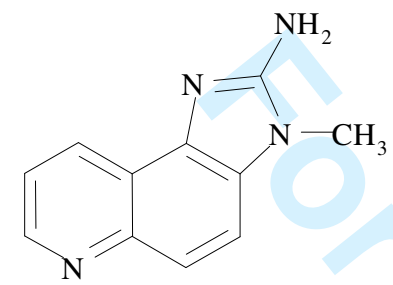

IQ

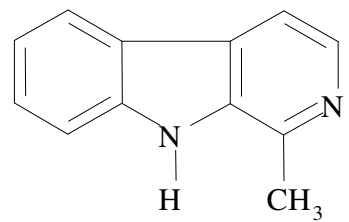

Harman

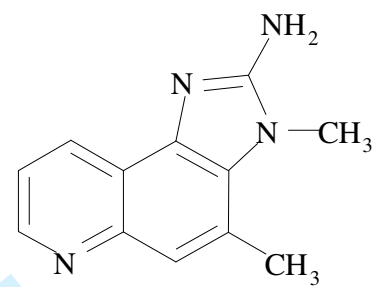

MeIQ

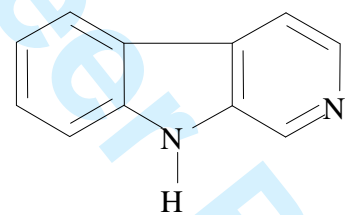

Norharman

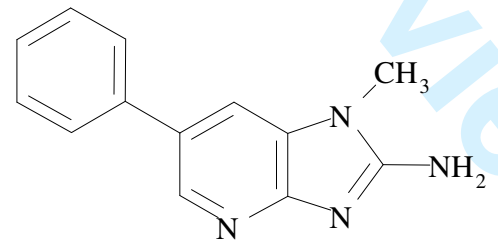

PhIP

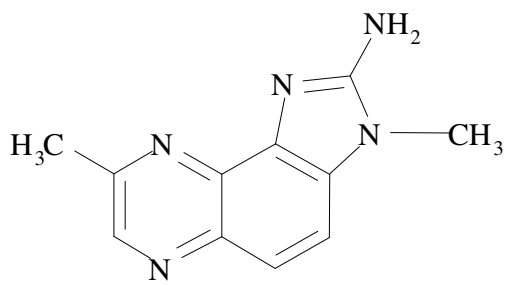

MeIQx

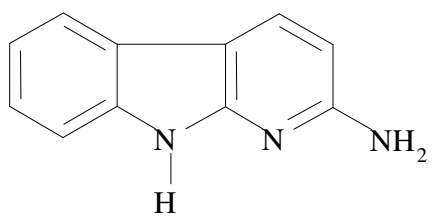

$\mathrm{A} \alpha \mathrm{C}$

31

32

33

34

35

36

37

39

40

41

42

43

44

45

46

47

48

49

50

51

52

53

54

55

56

57

58

59

60

http://mc.manuscriptcentral.com/tfac Email: fac@tandf.co.uk 
Figure 2
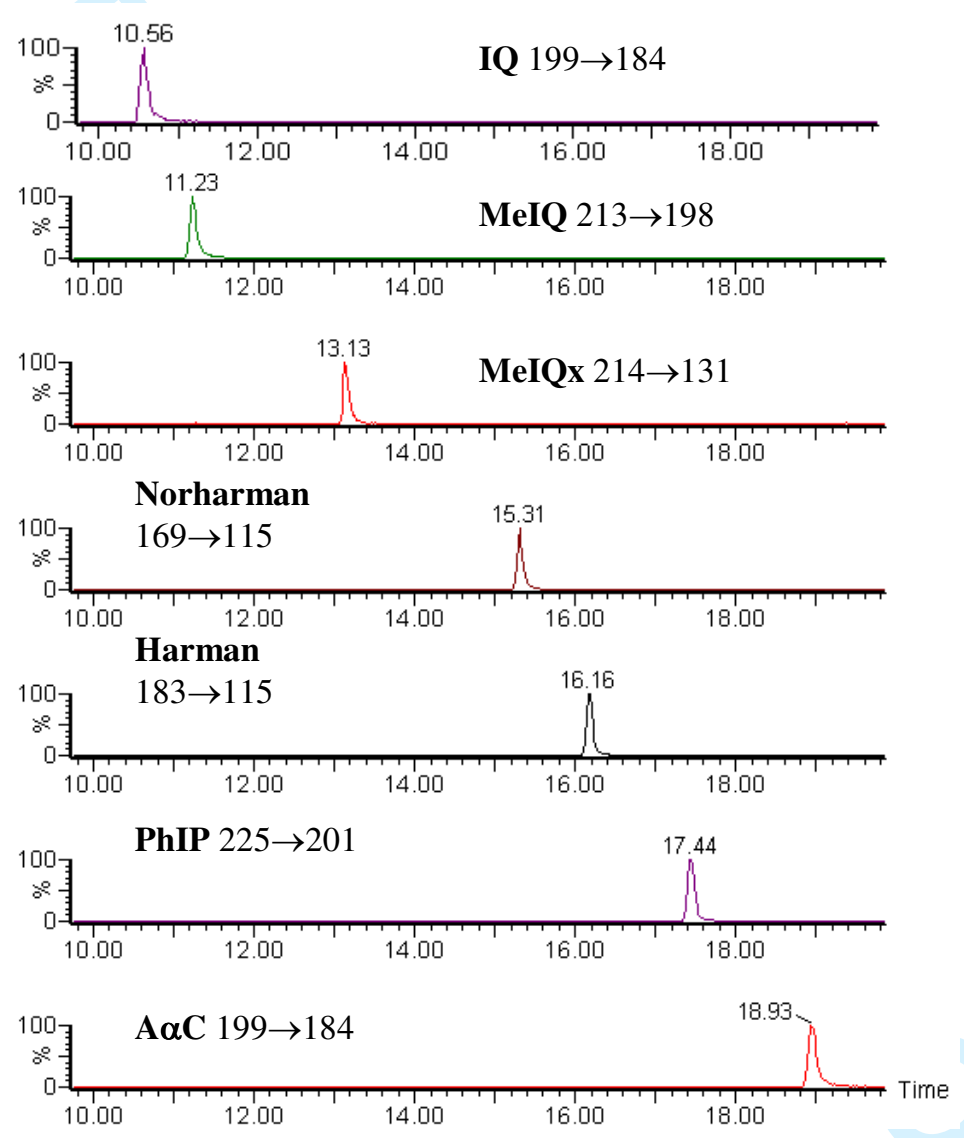
Figure 3
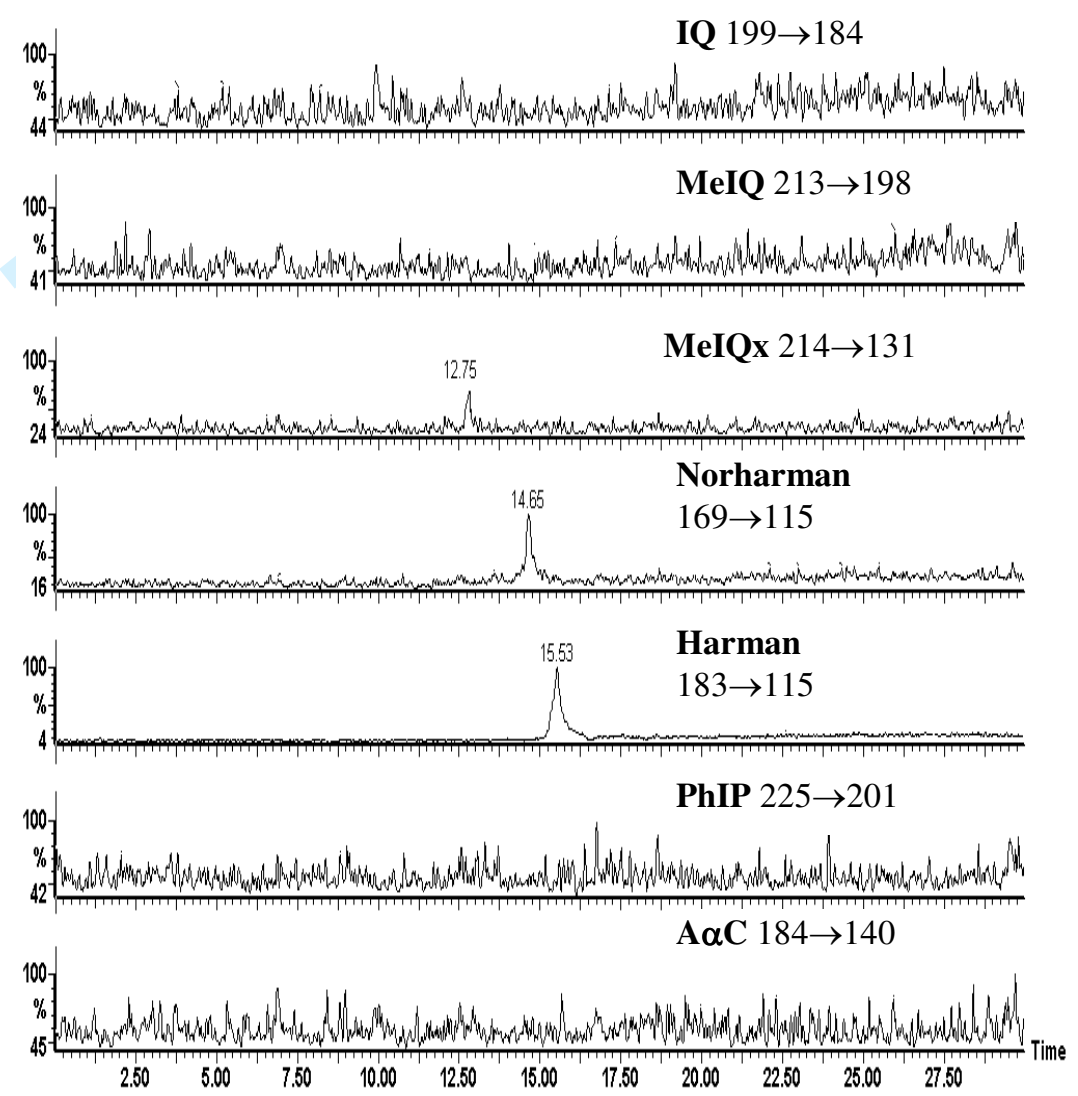